\title{
Rates, variability, and associated factors of polypharmacy in nursing home patients
}

This article was published in the following Dove Press journal:

Clinical Interventions in Aging

27 November 2013

Number of times this article has been viewed

Yichayaou Beloosesky ${ }^{1,3}$

Olga Nenaydenko²

Revital Feige Gross Nevo ${ }^{1,3}$

Abraham Adunsky ${ }^{2,3}$

Avraham Weiss ${ }^{1,3}$

'Department of Geriatrics, Rabin

Medical Center, Beilinson Hospital,

Petah Tikva, ${ }^{2}$ Department of Geriatric

Rehabilitation, Sheba Medical Center,

Tel Hashomer, ${ }^{3}$ Sackler School of

Medicine, Tel Aviv University, Petah

Tikva, Israel
Correspondence: Yichayaou Beloosesky Rabin Medical Center, Beilinson Hospital, Petah Tikva, 49372, Israel

Tel +97239376820

Fax +97239376817

Email beloy@clalit.org.il

Avraham Weiss

Department of Geriatrics,

Rabin Medical Center, Beilinson Hospital,

Petah Tikva, 49372, Israel

Tel +97239376821

Email avraham@clalit.org.il
Objectives: To determine the rate and variability of polypharmacy in nursing home $(\mathrm{NH})$ residents and investigate its relationship to age, sex, functional status, length of stay, and comorbidities.

Methods: We conducted a cross sectional, multicenter study that included six nursing homes. Demographic, clinical characteristics, Charlson comorbidity index (CCI), the number and classes of chronic medications, rate of polypharmacy $>5$ drugs (per day) and polypharmacy $>7$ drugs (per day) were recorded.

Results: Nine hundred and ninety-three residents were included; 750 (75.5\%) fully dependent residents and 243 (24.5\%) mobile demented residents requiring institutional care. The mean age was $85.04 \pm 7.55(65-108)$ years. The mean rates of polypharmacy $>5$ drugs and polypharmacy $>7$ drugs were $42.6 \%$ and $18.6 \%$, respectively. Differences in polypharmacy $>5$ drugs and polypharmacy $>7$ drugs were observed in NHs $24.7 \%-56 \%$ and $4.9 \%-30.4 \%$, respectively $(P<0.001)$. Mean number of chronic drugs per resident was $5.14 \pm 2.60$ from $3.81 \pm 2.24$ to $5.95 \pm 2.73(P<0.001)$. No differences in polypharmacy were found between sex and fully dependent versus mobile demented residents. The most common medications taken were for gastrointestinal, neurological, and cardiovascular disorders. Regression analysis revealed four independent variables for polypharmacy $>5$ drugs: groups aged $75-84$ and $>85$ relative to 65-74, odds ratio (OR) 0.46 (95\% confidence interval [CI] 0.27-0.78) $P=0.004$, OR 0.35 (95\% confidence interval 0.19-0.53), respectively, $P<0.001$; length of stay $>2$ years, OR 0.51 (95\% CI 0.36-0.73) $P<0.001$; CCI, OR 1.58 (95\% CI 1.42-1.75) $P<0.001$; and feeding tube versus normal feeding, OR 0.27 (95\% CI 0.12-0.60) $P=0.001$.

Conclusion: Rates of polypharmacy in NHs are high with significant variability. Variability rates of polypharmacy, distinct residents' characteristics, and excessive use of certain drug groups may indicate that a decrease in medication is potentially feasible.

Keywords: polypharmacy, nursing homes, variability, dementia, dependent, residents

\section{Introduction}

Polypharmacy is the use of multiple medications by a patient, including prescription as well as over-the-counter drugs, and also those medications used in complementary and alternative medicine, including dietary supplements. ${ }^{1}$ Polypharmacy can be defined quantitatively, ie, above a predefined number of drugs, although there is still no consensus as to the number of drugs; or defined qualitatively, referring to drugs used without clear clinical indication, regardless of the drug number. ${ }^{2}$ Although thresholds used for polypharmacy investigations have been reported to be between two to nine drugs, or more, ${ }^{2,3}$ most authors have used the threshold of five or more prescription drugs. ${ }^{4,5}$ 
Some authors have defined polypharmacy as the use of six to nine drugs, and above that number, described as excessive polypharmacy. ${ }^{6}$

Polypharmacy effects are numerous and include adverse drug reactions, responsible for $5 \%-6 \%$ of all hospitalizations $^{7}$ and up to $12 \%$ in the elderly population. ${ }^{8}$ Other effects of polypharmacy include interactions between drugs, and between drugs and nutrients; ${ }^{9}$ nonadherence that increases in parallel with the number of drugs $;^{8}$ and inappropriate prescribing that is correlated with the number of drugs. ${ }^{10,11}$ which is highly prevalent in nursing home (NH) patients. ${ }^{9,12}$

In an extensive review of English-language original articles starting from 1990 including approximately 84,000 patients, Tamura et $\mathrm{al}^{13}$ reported that polypharmacy in NHs was consistently associated with a high incidence of potentially inappropriate drug use and an increase of adverse drug reactions, drug-drug interactions, and hospitalizations.

The Slone survey, ${ }^{14}$ an ongoing study of a random sample of 2,590 noninstitutionalized individuals aged at least 18 years, revealed that $57 \%$ of women and $44 \%$ of men $>65$ years old in the USA took five or more drugs per day during the preceding week. Similar use of drugs was found in Europe, where $51 \%$ of the older population took at least six drugs per day. ${ }^{15}$ In the 2004 National Nursing Home Survey conducted in the USA, $40 \%$ of the patients consumed at least nine different drugs per day. The odds of polypharmacy were higher for female residents, those who had more than three comorbidities, those who needed assistance with four or fewer activities of daily living, and those who received care in a not-for-profit facility. ${ }^{16}$

In a very large Canadian study, including all long-term care homes in Ontario, the polypharmacy rate of $\geq 9$ drugs was $15.5 \%$ with a large variability $(7.9 \%-26.2 \%)$ between the institutions. Residents of the long-term care homes having polypharmacy, experienced more comorbidites than those taking fewer drugs. ${ }^{17}$ Data from the Canadian National Population Health Survey revealed a polypharmacy $\geq 5$ drug rate of $53 \%$ among residents living in long-term care institutions; this level of polypharmacy was associated with comorbidities and chronic pain. ${ }^{18}$ High polypharmacy rates were also found in the European SHELTER study investigating medication use among nursing home residents: $49.7 \%$ for five to nine drugs and $24.3 \%$ for $\geq 10$ drugs. ${ }^{19}$ Polypharmacy was directly correlated with comorbidities and chronic pain, and indirectly with age and functional and cognitive decline. ${ }^{19}$ Other studies from the
Singapore and the Netherlands also demonstrated a high rate of polypharmacy in NH residents..$^{20,21}$

Our objectives were to investigate polypharmacy in NHs in central Israel and to determine its rates, variability between institutions, and its relationship to age, sex, functional status, length of stay, and comorbidities.

\section{Methods}

Study design

Following the approval of Beilinson Hospital's Institutional Review Board, Rabin Medical Center, (which belongs to the Clalit Health Services and where the principal investigator is a senior staff member), demographic, clinical characteristics, and data on chronic medication use was cross-sectionally collected from six NHs (four for-profit and two not-for-profit long-term care institutions). For procedural and ethical reasons, only residents insured by Clalit Health Services, the major nongovernmental nonprofit health organization in Israel (insuring 53\% of the total population, and approximately $70 \%$ of the population $>75$ years), were included in the study. Each $\mathrm{NH}$ included two separate resident departments: one for fully dependent patients; and the other for mobile, demented patients requiring institutional care.

\section{Data collection and measures}

Data collected from the medical files in each $\mathrm{NH}$ from November 2011 to February 2012 included age, sex, length of stay (LOS), and comorbidities. Only residents aged $\geq 65$ who had been institutionalized for at least 1 month were included. The Charlson comorbidity index (CCI) was calculated for each patient. ${ }^{22}$ Residents were grouped as those functionally fully dependent (among whom the large majority had at least mild to moderate dementia) and those who were mobile and demented. Only chronic medications given orally, by inhalation, or eye drops, given for at least 1 month prior to data collection, were recorded for each resident (complementary, over-the-counter, and nutritional supplements were not recorded). In Israel, only physicians prescribe drugs (the nurse practitioner concept, ie, nurses with autonomy to prescribe drugs, is still in its early stages). All chronic medications were regrouped into drug classes. Two types of polypharmacy were determined: polypharmacy defined as $>5$ drugs/day and polypharmacy defined as $>7$ drugs/day. We defined the threshold for polypharmacy as six or more drugs/ day, as did previous publications that considered six drugs as the minimum required for polypharmacy. ${ }^{6}$ The threshold of eight or more drugs/day was determined by the Israeli 
Ministry of Health and is required to be noted in the medical files of all $\mathrm{NH}$ residents in Israel.

\section{Statistical analysis}

The one-way analysis of variance (ANOVA) was used for testing the relationship between normally distributed continuous variables and categorical variables (ie, comparing the mean number of drugs used between NHs, or comparing the means of LOS, age, and CCI score between NHs). The chi-square test examined the relationship between categorical variables (ie, compared the mean rates of polypharmacy $>5$ drugs and polypharmacy $>7$ drugs between NHs or between age groups, or between fully functionally dependent and mobile demented residents). Spearman's correlation was used to measure the relationship between number of medications and LOS. Forward stepwise logistic regression analysis determined the independent variables affecting polypharmacy $>5$ drugs. A $P$-value of $<0.05$ was considered significant.

\section{Results}

Nine hundred and ninety-three residents (708 women, 285 men) were included in the study; this number represents about $70 \%$ of all residents residing in the six institutions. Seven hundred and fifty (75.5\%) were fully dependent, and $243(24.5 \%)$ were mobile demented residents requiring institutional care; 97 (9.8\%) residents had feeding tubes. The mean age was $85.04 \pm 7.55$ years (range 65-108 years). Residents' distribution according to $\mathrm{NH}$ and age groups are detailed in Table 1. The number of drugs per resident varied from none to 17; Table 2 describes the rates of main drug classes.

Mean rates of polypharmacy $>5$ drugs and polypharmacy $>7$ drugs were $42.6 \%$ and $18.6 \%$, respectively.

Table I Patient distribution according to nursing home and age groups

\begin{tabular}{ll}
\hline Parameters & $\begin{array}{l}\text { Patient } \\
\text { number (\%) }\end{array}$ \\
\hline Nursing home & \\
I & $248(25)$ \\
2 & $197(19.8)$ \\
3 & $195(19.6)$ \\
4 & $147(14.8)$ \\
5 & $81(8.2)$ \\
6 & $125(12.6)$ \\
Age groups & \\
$65-74$ & $103(10.4)$ \\
$75-84$ & $324(32.6)$ \\
$\geq 85$ & $566(57.0)$ \\
\hline
\end{tabular}

Note: The numbers under the "Nursing home" designation are for purposes of data separation only, they have no other significance.
Table 2 Rates of main drug classes

\begin{tabular}{ll}
\hline Drug groups & Rate \% \\
\hline H2 blockers and proton-pump inhibitors (PPIs) & 48.0 \\
Benzodiazepines & 46.9 \\
Antiplatelet drugs & 40.6 \\
Neuroleptics & 38.6 \\
ACE inhibitors and ARBs & 31.0 \\
SSRls and SNRIs & 30.9 \\
Beta blockers & 29.3 \\
Diuretics & 26.9 \\
Lipid lowering drugs & 22.2 \\
Antidiabetic drugs & 21.4 \\
Calcium blockers & 21.1 \\
Levothyroxine & 18.1 \\
Anti-Parkinsonian drugs & 14.2 \\
Medical eye drops & 11.9 \\
Nonbenzodiazepine sleeping pills & 10.9 \\
Antiepileptic drugs & 9.0 \\
Alpha blockers & 8.9 \\
Anticoagulants & 8.1 \\
Antiarrhythmic drugs & 6.0 \\
Analgesics & 4.8 \\
Steroids & 4.5 \\
Nitrates & 3.9 \\
Acetylcholinesterase inhibitors and memantine & 3.2 \\
Bisphosphonates & 3.1 \\
Chronic use of inhalations & 2.2 \\
\hline Abbrevitions ACE, angotesingonver
\end{tabular}

Abbreviations: ACE, angiotensin-converting enzymes; $A R B s$, angiotensin receptor blockers; SSRIs, selective serotonin reuptake inhibitors; SNRIs, serotoninnorepinephrine reuptake inhibitors.

However, there were significant variations between NHs in polypharmacy of $>5$ drugs and polypharmacy of $>7$ drugs: $24.7 \%-56 \%$ and $4.9 \%-30.4 \%$, respectively $(P<0.001)$. The mean number of drugs per resident was $5.14 \pm 2.60$ with significant differences between NHs, ranging from 3.81 \pm 2.24 to $5.95 \pm 2.73(P<0.001)$. There were no differences in polypharmacy rates between for-profit and not-for-profit institutions. It is worth noting that the $\mathrm{NH}$ with the lower polypharmacy rate and mean drugs per resident was mainly occupied by mobile demented patients and maintained a more specialized medical approach to demented residents. There were no differences in the rate of polypharmacy $>5$ drugs or

Table 3 Rates of polypharmacy according to functional status and sex

\begin{tabular}{llll}
\hline Polypharmacy & $\begin{array}{l}\text { Fully } \\
\text { dependent } \\
\text { (750 residents) }\end{array}$ & $\begin{array}{l}\text { Mobile } \\
\text { demented } \\
\text { (243 residents) }\end{array}$ & $\begin{array}{l}\text { Male/female } \\
\text { ratio }\end{array}$ \\
\hline $\begin{array}{l}\text { Polypharmacy } \\
>5 \text { drugs/day }\end{array}$ & $43.5 \%$ & $39.9 \%$ & $125 / 298$ \\
$\begin{array}{l}\text { (423 residents) } \\
\begin{array}{l}\text { Polypharmacy } \\
>7 \text { drugs/day }\end{array}\end{array}$ & $19.4 \%$ & $16.5 \%$ & $55 / 130$ \\
(185 residents) & & & \\
\hline
\end{tabular}


polypharmacy $>7$ drugs between residents grouped by sex or between fully dependent and mobile demented patient groups (table 3 ). There were no differences between NHs in the number of residents in each age group $(P=0.4)$, nor in their mean ages $(P=0.13)$.

The rate of polypharmacy $>5$ drugs and polypharmacy $>7$ drugs decreased with age: $58.3 \%, 44 \%, 39 \%$, and $34 \%, 20.4 \%, 14.8 \%$ for ages $65-74,75-84$, and $>85$, respectively $(P=0.001, P<0.001)$. The mean LOS was $36.4 \pm 35.3$ months, with significant variations between $\mathrm{NHs}$, from $28.1 \pm 26.6$ to $50.6 \pm 39.3$ months $(P<0.001)$. An inverse correlation was found between mean number of drugs per resident and $\operatorname{LOS}(r=-0.178, P<0.001)$. Four hundred seventy-eight residents were institutionalized $<2$ years; $514,>2$ years. The rate of polypharmacy, both for polypharmacy $>5$ drugs and $>7$ drugs, was higher in residents institutionalized $<2$ years, compared with those institutionalized $>2$ years: $50.2 \%$ versus (vs) $35.6 \%$, and $23.4 \%$ vs $14.2 \%$, respectively $(P<0.001)$.

The mean CCI score was $2.45 \pm 1.59$, with significant variations between $\mathrm{NHs}$, from $2.74 \pm 1.74$ to $1.97 \pm 1.2$ $(P=0.001)$. No relationship was found between age and CCI score. The CCI score was higher in residents with polypharmacy $>5$ drugs and polypharmacy $>7$ drugs compared to those without: $2.99 \pm 1.69$ vs $2.04 \pm 1.38$ and $3.44 \pm 1.76$ vs $2.21 \pm 1.46$, respectively $(P<0.001)$.

Both polypharmacy $>5$ drugs and polypharmacy $>7$ drugs were less prevalent in residents with feeding tubes: $20.6 \%$ vs $45.1 \%$ and $8.2 \%$ vs $19.8 \%$, respectively $(P=0.004)$. Table 4 summarizes the demographic and clinical parameters according to polypharmacy $>5$ drugs and polypharmacy $>7$ drugs.

Because several variables were found associated with polypharmacy, we conducted a forward stepwise logistic regression analysis to determine the independent variables. Included were age groups, presence or absence of feeding tube, LOS of 2 years or less, CCI score and functional resident groups (fully dependent vs mobile demented residents).
Four independent variables for polypharmacy $>5$ drugs were found: age group 75-84 and $>85$ years old relative to $65-74$, odds ratio (OR) 0.46 (95\% confidence interval [CI] 0.27-0.78) $P=0.004$, OR 0.35 (95\% CI 0.19-0.53) respectively, $P<0.001$; LOS $>2$ years, OR $0.51(95 \% \mathrm{CI}$ 0.36-0.73) $P<0.001$; CCI, OR 1.58 (95\% CI 1.42-1.75) $P<0.001$; and feeding tube vs normal feeding, OR $0.27(95 \%$ CI 0.12-0.60) $P=0.001$.

\section{Discussion}

We determined the rate of polypharmacy in a large group of residents from several NHs in Israel and found a large variability among them. Polypharmacy was more common in the younger age group, in residents institutionalized $<2$ years, in those with a higher comorbidity index, and in residents who did not need a feeding tube.

The rate of polypharmacy $>5$ drugs appeared to be much lower than the rate reported in the National Nursing Home Survey conducted in the USA, where $40 \%$ of the patients used at least nine drugs. ${ }^{16}$ However, in the American survey, almost $12 \%$ of the residents were $<65$ years old and only $45 \%$ were $>85$ years, compared with $57 \%$ of the residents $>85$ years in our study, in whom polypharmacy was significantly lower. In the Canadian study, including all the long-term care homes in Ontario, ${ }^{17}$ the polypharmacy rate of $\geq 9$ drugs was $15.5 \%$, very similar to the rate of polypharmacy $>7$ drugs in the present study. Moreover, in 57 NHs in Europe, the mean polypharmacy rate of five to nine drugs was $49.7 \%$, comparable to that in our study. ${ }^{19}$

Variability of polypharmacy between NHs was observed and was more marked in other countries. In the Canadian study, polypharmacy varied between $7.9 \%$ and $26.2 \%{ }^{17}$ in the European study between $8.8 \%$ in Italy and up to $56.7 \%$ in Finland. ${ }^{19}$ The reasons for this variability between institutions probably results from multiple factors such as number of prescriptions and treating physicians, different approaches to drug prescriptions between physicians (ie, strict adherence to guidelines or a more permissive or individual

Table 4 Main clinical parameters, mean number of drugs/day and rates of polypharmacy in the six nursing homes

\begin{tabular}{|c|c|c|c|c|c|c|}
\hline $\begin{array}{l}\text { Nursing } \\
\text { homes }\end{array}$ & $\begin{array}{l}\text { Mean age } \\
( \pm \text { SD })\end{array}$ & $\begin{array}{l}\text { Mean number of } \\
\text { drugs/day ( } \pm \text { SD) }\end{array}$ & $\begin{array}{l}\text { Mean LOS in } \\
\text { months }( \pm S D)\end{array}$ & $\begin{array}{l}\text { Mean } \mathrm{CCl} \\
\text { score }( \pm \mathrm{SD})\end{array}$ & $\begin{array}{l}\text { Rate (\%) of polypharmacy } \\
>5 \text { drugs/day }\end{array}$ & $\begin{array}{l}\text { Rate }(\%) \text { of polypharmacy } \\
>7 \text { drugs/day }\end{array}$ \\
\hline 1 & $83.9(7.3)$ & $5.08(2.8)$ & $28.1(26.6)$ & $2.37(1.5)$ & 42.1 & 20.6 \\
\hline 2 & $85.2(8.0)$ & $5.29(2.5)$ & $50.6(39.4)$ & $2.54(1.6)$ & 45.2 & 17.3 \\
\hline 3 & $85.5(7.8)$ & $5.20(2.5)$ & 31.3 (38.7) & $2.23(1.4)$ & 42.6 & 17.9 \\
\hline 4 & $85.9(7.5)$ & $5.00(2.4)$ & $37.4(39.2)$ & $2.74(1.7)$ & 38.8 & 15.6 \\
\hline 5 & $85.5(6.7)$ & $3.81(2.2)$ & $43.3(28.8)$ & $1.97(1.2)$ & 24.7 & 4.9 \\
\hline 6 & $85.0(7.5)$ & $5.1(2.6)$ & $32.9(29.5)$ & $2.72(1.9)$ & 56.0 & 30.4 \\
\hline
\end{tabular}

Abbreviations: SD, Standard deviation; LOS, length of stay; $\mathrm{CCl}$, Charlson comorbidity index. 
approach, as well as from economic restrictions). ${ }^{17,19}$ The socioeconomic class of residents might be very different between NHs, greatly affecting medication use. This occurred in our present study, where one of the NHs had the lowest polypharmacy rate and was occupied mainly by mobile demented residents with a lower comorbidity index. This observation is somewhat contradictory to the finding that there were no differences in polypharmacy between fully dependent and mobile demented resident groups. Our assumption is that in the other $5 \mathrm{NHs}$, the mobile demented residents, although regrouped in specific departments, were not treated very differently pharmacologically as compared with other residents from departments of fully dependent residents. However, in the sixth $\mathrm{NH}$, where almost all residents were mobile demented patients, there was a more specialized, oriented, and comprehensive approach that should have reduced drug prescriptions. Indeed, other large studies revealed a lower polypharmacy rate in demented residents compared with others. ${ }^{23,24}$

This vast polypharmacy variability between NHs emphasizes, from our point of view, the real possibility if not the necessity to reduce polypharmacy rates. In fact, some authors have demonstrated that extensive reduction of unnecessary medications in older patients in the community and in NHs is possible - and probably beneficial. ${ }^{25,26}$

The drugs most frequently used were prescribed for disorders of the gastrointestinal, nervous, and cardiovascular systems (Table 2). Similar drug distributions were also described in NHs from other countries. ${ }^{16-19,23}$ For example, $38.6 \%$ of residents in our study used antipsychotic drugs, whereas in other studies, the use varied from $25.9 \%{ }^{16}$ to $42.9 \%{ }^{23} \mathrm{We}$ did not investigate the inappropriate prescribing, but we presume that we would have found it as common, as has been found in Norway $(25.3 \%),{ }^{24}$ the USA $(37.5 \%),{ }^{27}$ and Singapore (up to $70 \%)^{20}$

Regression analysis of our data determined that being part of a younger age group is a risk factor for polypharmacy, and some large surveys demonstrated the same results, ${ }^{16,18,23}$ whereas others showed no age effect on polypharmacy. ${ }^{28,29}$ There are several plausible explanations for the inverse relationship between age and drug use. Firstly, residents who reach an older age are a priori healthier and consequently need fewer medications. Secondly, in an older aged population, because of frailty and comorbidities, physicians are more cautious and limit the number of prescribed drugs. ${ }^{29}$ Frailty is prevalent in old age and largely signifies a decrease in the physiologic and functioning reserves and an inability to adequately respond to stress. ${ }^{30}$ Frail older people have multiple comorbidities, polypharmacy, and often exhibit cognitive and functional decline that renders them highly vulnerable to adverse drug reactions, geriatric syndromes, and hospitalizations. Several recent studies have revealed a strong association of polypharmacy with frailty. ${ }^{31,32}$

Some authors have investigated the relationship between LOS and polypharmacy. A comparison of these investigations is difficult because definitions of LOS vary considerably, from months to years..$^{29}$ However, Dwyer et al ${ }^{16}$ reported a lower rate of polypharmacy of $\geq 9$ drugs in residents institutionalized $>5$ years compared with those institutionalized $<5$ years. This finding concurs with our results, though we studied polypharmacy $>5$ drugs and compared residents institutionalized $<2$ years vs $>2$ years. Residents who have been institutionalized for several years are generally medically stable, might live longer, and are therefore healthier and need fewer drugs.

The CCI was also found to be an independent risk factor for polypharmacy. Dwyer et $\mathrm{al}^{16}$ found that the polypharmacy rate increased up to three-fold if the number of comorbidities exceeded ten, compared with only three comorbidities. ${ }^{16}$ Bronskill et al ${ }^{17}$ showed that when Charlson-Deyo scores ${ }^{33}$ (an adaptation of the $\mathrm{CCI}$ designed for use with medical records for research relying on International Classification of Diseases ${ }^{33}$ [ICD-9-CM] diagnosis and procedure codes) are $\geq 2$, the rate of polypharmacy $\geq 9$ almost doubles. Elseviers et $\mathrm{al}^{23}$ reported a direct relationship between the number of comorbidities and number of chronic drugs ingested.

Polypharmacy was almost four times less prevalent in residents with a feeding tube. We believe that these residents were treated with minimal, and only essential, drugs due to their poor status, their prognosis, and the limitations of drug administration through the feeding tube.

This study has some limitations. Only six NHs from the central and most populated areas of the country were included. However, because Israel is a small country and the quasi-totality of NHs are closely supervised under strict regulations of the Israeli Ministry of Health (eg, number and qualifications of physicians, nurses, physiotherapists, occupational therapists, dietitians, social workers, and other auxiliary staff, nutritional parameters, number of residents/ department, building regulations) and because we included for- and not-for-profit institutions, we believe that our sample is representative regarding age, sex profiles, and clinical characteristics of Israeli NHs. We did not investigate drug appropriateness, potential interactions, or adverse drug reactions, which are very important qualitative parameters; however, they are not within the scope of the present study. 
Despite its limitations, this study is, to the best of our knowledge, the largest study describing and analyzing drug use in NHs in Israel. We conclude that rates of polypharmacy in NHs are high, with a significant variability. The variability in rates of polypharmacy, distinct residents' characteristics, and excessive use of certain drug groups, may indicate that a decrease in medication is potentially feasible.

\section{Acknowledgments}

The authors thank Mrs Phyllis Curchack Kornspan for her editorial services.

\section{Disclosure}

The authors have no conflicts of interest relating to this article.

\section{References}

1. Hovstadius B, Petersson G. Factors leading to excessive polypharmacy. Clin Geriatr Med. 2012;28:159-172.

2. Shah BM, Hajjar ER. Polypharmacy, adverse drug reactions, and geriatric syndromes. Clin Geriatr Med. 2012;28(2):173-186.

3. Fulton MM, Allen ER. Polypharmacy in the elderly: a literature review. J Am Acad Nurse Pract. 2005;17(4):123-132.

4. Viktil KK, Blix HS, Moger TA, Reikvam A. Polypharmacy as commonly defined is an indicator of limited value in the assessment of drug-related problems. Br J Clin Pharmacol. 2007;63(2):187-195.

5. Haider SI, Johnell K, Thorslund M, Fastbom J. Analysis of the association between polypharmacy and socioeconomic position among elderly aged $\geq 77$ years in Sweden. Clin Ther. 2008;30(2):419-427.

6. Jyrkkä J, Enlund H, Korhonen MJ, Sulkava R, Hartikainen S. Polypharmacy status as an indicator of mortality in an elderly population. Drugs Aging. 2009;26(12):1039-1048.

7. Kongkaew C, Noyce PR, Ashcroft DM. Hospital admissions associated with adverse drug reactions: a systematic review of prospective observational studies. Ann Pharmacother. 2008;42(7):1017-1025.

8. Hajjar ER, Cafiero AC, Hanlon JT. Polypharmacy in elderly patients. Am J Geriatr Pharmacother. 2007;5(4):345-351.

9. Colley CA, Lucas LM. Polypharmacy: the cure becomes the disease. J Gen Intern Med. 1993;8(5):278-283.

10. Mansur N, Weiss A, Beloosesky Y. Is there an association between inappropriate prescription drug use and adherence in discharged elderly patients? Ann Pharmacother. 2009;43(2):177-184.

11. Steinman MA, Landefeld CS, Rosenthal GE, Berthenthal D, Seen S, Kaboli PJ. Polypharmacy and prescribing quality in older people. $\mathrm{JAm}$ Geriatr Soc. 2006;54(10):1516-1523.

12. Aparasu RR, Mort JR. Inappropriate prescribing for the elderly: beers criteria-based review. Ann Pharmacother. 2000;34(3):338-346.

13. Tamura BK, Bell CL, Inaba M, Masaki KH. Outcomes of polypharmacy in nursing home residents. Clin Geriatr Med. 2012;28(2):217-236.

14. Kaufman DW, Kelly JP, Rosenberg L, Anderson TE, Mitchell AA. Recent patterns of medication use in the ambulatory adult population of the United States: the Slone survey. JAMA. 2002;287(3):337-344.

Clinical Interventions in Aging

\section{Publish your work in this journal}

Clinical Interventions in Aging is an international, peer-reviewed journal focusing on evidence-based reports on the value or lack thereof of treatments intended to prevent or delay the onset of maladaptive correlates of aging in human beings. This journal is indexed on PubMed Central, MedLine, the American Chemical Society's 'Chemical Abstracts
15. Fialová D, Topinková E, Gambassi G, et al. Potentially inappropriate medication use among elderly home care patients in Europe. JAMA. 2005;293(11):1348-1358.

16. Dwyer LL, Han B, Woodwell DA, Rechtsteiner EA. Polypharmacy in nursing home residents in the United States: results of the 2004 National Nursing Home Survey. Am J Geriatr Pharmacother. 2010;8(1):63-72.

17. Bronskill SE, Gill SS, Paterson JM, Bell Cm, Anderson GM, Rochon PA. Exploring variation in rates of polypharmacy across long term care homes. J Am Med Dir Assoc. 2012;13(3):309. e15-e21.

18. Ramage-Morin PL. Medication use among senior Canadians. Health Rep. 2009;20(1):37-44.

19. Onder G, Liperoti R, Fialova D, et al. Polypharmacy in nursing home in Europe: results from the SHELTER study. J Gerontol A Biol Sci Med Sci. 2012;67(6):698-704.

20. Mamun K, Lien CT, Goh-Tan CY, Ang WS. Polypharmacy and inappropriate medication use in Singapore nursing homes. Ann Acad Med Singapore. 2004;33(1):49-52.

21. Finkers F, Maring JG, Boersma F, Taxis K. A study of medication reviews to identify drug-related problems of polypharmacy patients in the Dutch nursing home setting. J Clin Pharm Ther. 2007;32(5):469-476.

22. Charlson ME, Pompei P, Ales KL, MacKenzie CR. A new method of classifying prognostic comorbidity in longitudinal studies: development and validation. J Chronic Dis. 1987;40(5):373-383.

23. Elseviers MM, Vander Stichele RR, Van Bortel L. Drug utilization in Belgian nursing homes: impact of residents' and institutional characteristics. Pharmacoepidemiol Drug Saf. 2010;19(10):1041-1048.

24. Nygaard HA, Naik M, Ruths S, Straand J. Nursing-home residents and their drug use: a comparison between mentally intact and mentally impaired residents. The Bergen district nursing home (BEDNURS) study. Eur J Clin Pharmacol. 2003;59(5-6):463-469.

25. Garfinkel D, Zur-Gil S, Ben-Israel J. The war against polypharmacy: a new cost-effective geriatric-palliative approach for improving drug therapy in disabled elderly people. Isr Med Assoc J. 2007;9(6):430-434.

26. Garfinkel D, Mangin D. Feasibility study of a systematic approach for discontinuation of multiple medications in older adults: addressing polypharmacy. Arch Intern Med. 2010;170(18):1648-1654.

27. Tjia J, Rothman MR, Kiely DK, et al. Daily medication use in nursing home residents with advanced dementia. J Am Geriatr Soc. 2010;58(5):880-888.

28. Bergman A, Olsson J, Carlsten A, Waern M, Fastbom J. Evaluation of the quality of drug therapy among elderly patients in nursing homes. Scand J Prim Health Care. 2007;25(1):9-14.

29. Tamura BK, Bell CL, Inaba M, Masaki KH. Factors associated with polypharmacy in nursing home residents. Clin Geriatr Med. 2012;28(2): 199-216.

30. Partridge JS, Harari D, Dhesi JK. Frailty in the older surgical patient: a review. Age Ageing. 2012;4(2):142-147.

31. Gnjidic D, Hilmer SN, Blyth FM, et al. Polypharmacy cutoff and outcomes: five or more medicines were used to identify communitydwelling older men at risk of different adverse outcomes. $J$ Clin Epidemiol. 2012;65(9):989-995.

32. Gnjidic D, Hilmer SN, Blyth FM, et al. High-risk prescribing and incidence of frailty among older community-dwelling men. Clin Pharmacol Ther. 2012;91(3):521-528.

33. Deyo RA, Cherkin DC, Ciol MA. Adapting a clinical comorbidity index for use with ICD-9-CM administrative databases. J Clin Epidemiol. 1992;45(6):613-619.

\section{Dovepress}

Service' (CAS), Scopus and the Elsevier Bibliographic databases. The manuscript management system is completely online and includes a very quick and fair peer-review system, which is all easy to use. Visit $\mathrm{http}: / /$ www.dovepress.com/testimonials.php to read real quotes from published authors. 